\title{
Capital Criativa da Europa: aspectos da criatividade urbana em Lisboa
}

\author{
Creative Capital of Europe: aspects of urban creativity in Lisbon
}

Sarita Cruz de Oliveira Ost. Universidade Feevale. E-mail: saritacruz@gmail.com Mary Sandra Guerra Ashton. Universidade Feevale. E-mail: marysga@feevale.br Marcos Emílio Santuário. Universidade Feevale. E-mail: santuario@feevale.br

\section{RESUMO}

Esse estudo tem como tema central a cidade de Lisboa e sua relação com a criatividade. Os investimentos na indústria criativa utilizados como um dos pilares estratégicos para o fim da crise, renderam a transformação de Lisboa em um polo de artistas, pensadores e criadores de várias partes do mundo, se destacando na área da cultura e da criatividade em nível mundial. Nesse contexto, este trabalho tem como objetivo analisar se os elementos que tornaram Lisboa a Capital Criativa da Europa são percebidos pelos residentes e visitantes. Para tanto, utilizou-se o método exploratório descritivo por meio de revisão bibliográfica e pesquisa de campo com análise de cunho qualitativo. Entre os resultados foi possível identificar que tanto os residentes quanto os visitantes de fato a reconhecem como uma Cidade Criativa. Pode-se destacar como os principais elementos presentes em Lisboa sob o ponto de vista dos participantes da pesquisa: uma cidade que mantém viva sua cultura, sua história e suas tradições, sendo contudo receptiva a novas ideias; após atravessar uma crise teve que se reinventar e por isto investe na indústria criativa como um dos principais clusters estratégicos; possui diversos eventos culturais e espaços disruptivos e criativos; a população percebe a mistura de uma Lisboa tradicional e uma Lisboa cosmopolita, moderna e voltada para o futuro.

Palavras-chave: Cidades criativas, Criatividade, Cultura, Desenvolvimento, Lisboa. 


\section{ABSTRACT}

This study has as its central theme the city of Lisbon and its relationship with creativity. Investments in the creative industry used as one of the strategic pillars for the end of the crisis have transformed Lisbon into a hub of artists, thinkers and creators from around the world, standing out in the world of culture and creativity. In this context, this work aims to analyze if the elements that made Lisbon the Creative Capital of Europe are perceived by residents and visitors. For that, he used the exploratory descriptive method through bibliographic review and field research with qualitative analysis. Among the results, it was possible to identify that both residents and visitors do recognize it as a Creative City. It can be highlighted as the main elements present in Lisbon from the point of view of the participants of the research: a city that keeps alive its culture, its history and its traditions, while still being receptive to new ideas; after having undergone a crisis, had to reinvent itself and for this it invests in the sectors of the creative industry as a strategic cluster; there are various events and disruptive and creative places; the population notes that there is a mix of a traditional Lisbon with a cosmopolitan, modern and forward-looking Lisbon.

Keywords: Creative Cities, Creativity, Culture, Development, Lisbon.

\section{INTRODUÇÃO}

Lisboa nunca esteve tão na moda. Academia, mídia, setores de turismo e a imprensa internacional nunca falaram tanto sobre Lisboa. Em 2008, Lisboa ganhou os holofotes da imprensa internacional em razão da crise econômica que impactou Portugal, tendo seu ápice em 2013, quando o governo adotou diversas medidas de austeridade, incluindo cassação de parte de $13^{\circ}$ salário e férias de sua população economicamente ativa. Entretanto, como estratégia para o fim da recessão, o governo português investiu parte dos escassos recursos na economia criativa. Tal investimento deu tão certo que em menos de dez anos depois, para além de ser o país da moda no turismo, Portugal viu a sua capital se transformar num polo de artistas, pensadores e criadores do mundo e agora recebe atenção mundial em razão do seu renascer (RIBOLDI, 2016). 
Em 2017, Lisboa ficou classificada na terceira posição na lista de cidades entre 500 mil e um milhão de habitantes em um importante relatório da Comissão Europeia que avalia a performance das cidades europeias nas áreas da Cultura e da Criatividade. Neste mesmo ano, foi eleita como a capital criativa da Europa (RODRIGUES, 2017).

Diante do acima exposto, justifica-se a pesquisa científica de Lisboa no contexto das Cidades Criativas, tendo relevância tal tema uma vez que a cidade tem ganhado cada vez mais premiações e posições de destaque na União Europeia e se consolidado de fato como uma Cidade Criativa sob os elementos que serão destacados no referencial teórico do presente artigo, bem como na pesquisa realizada. Esse estudo tem como objetivo analisar se os elementos que tornaram Lisboa a Capital Criativa da Europa são percebidos pelos residentes e visitantes. Desta forma, o problema de pesquisa consiste em apontar: quais são os elementos presentes em Lisboa que a constitui como Capital Criativa da Europa?

\section{Revisão de Literatura}

O termo Cidade Criativa surgiu no final da década de 1980, e foi cunhado como uma aspiração para que fossem criadas condições para que a população pudesse pensar, planejar e atuar na solução de problemas urbanos, e na implantação de melhorias para ampliar a geração de oportunidades e sua exploração (LANDRY, 2013; REIS, 2011; 2010; 2012; VIVANT, 2012).

O primeiro estudo específico sobre Cidades Criativas foi escrito por Charles Landry em 1990 - Glasgow: The Creative City and its Cultural Economy, seguido do estudo The Creative City in Britain and Germany em 1994. Logo após, em 1995 foi publicada uma versão mais curta destes estudos denominada The Creative City e uma versão mais completa foi publicada nos anos 2000 - The Creative City: A Toolkit for Urban Innovators - quando então o conceito de Cidade Criativa passou a se popularizar e ser difundido (LANDRY, 2013). 
O conceito de Cidade Criativa é controverso, uma vez que seguidamente é utilizado por cidades que desejam se autoafirmar como uma cidade criativa, sem, entretanto, buscar um entendimento detalhado e com embasamento no seu real significado e implicações (LANDRY, 2013). "Há um frenesi global que se prolifera à medida que os locais querem evoluir como Cidades Criativas ou simplesmente afirmar que são uma Cidade Criativa" (LANDRY, 2013, p. 9).

A capacidade de uma cidade em se constituir em uma cidade criativa é formada por sua história, sua cultura, sua configuração física e por suas condições operacionais globais. O modo de funcionamento de uma cidade pode promover ou inibir seu potencial criativo (LANDRY, 2013; REIS, 2012; FLORIDA, 2011 ). Para Landry (2013, p. 6) "liberar a criatividade dos cidadãos, das organizações e da cidade é um processo de outorga de poder que ajuda o potencial e é um recurso vital. É uma nova forma de capital e moeda".

A criatividade das pessoas que vivem e trabalham nas cidades é o que leva estas cidades para o sucesso. Ao crescerem e se desenvolverem, as cidades se tornam um laboratório intercultural para a descoberta e resolução de problemas urbanos que passam pela complexidade de fatores como a redução da desigualdade social, questões ecológicas e uma significação que vai além do consumismo (REIS, 2012; LANDRY, 2013).

Na Cidade Criativa, todos os cidadãos juntamente à esfera pública e privada são chamados e envolvidos pela criatividade em um ambiente de democratização de ideias, e não somente as pessoas que trabalham ou participam de alguma forma de atividades artísticas e culturais (LANDRY, 2013; REIS, 2010; REIS \& KAGEYAMA, 2011). "As cidades precisam criar condições para as pessoas pensarem, planejarem e agirem com imaginação" (LANDRY, 2013, P. 6).

As cidades devem ainda, dar conta dos inúmeros desafios que surgem da convivência entre as diferenças, sabendo administrar questões que contemplem aspectos econômicos, culturais e sociais, tais como, a diversidade e a sustentabilidade, repensando sempre seu papel frente à 
constante complexidade que abarca os espaços urbanos (LANDRY, 2013). Ainda de acordo com Landry (2013, p. 6), "um desafio crucial é como as cidades podem tornar visíveis seus atributos criativos em seu ambiente físico".

De acordo com Reis (2012), o conjunto de singularidades de uma cidade, pautado pelo seu ambiente social, cultural e econômico é o que a distingue

das demais cidades. Sendo a cidade formada pelas pessoas que nela circulam, trabalham e a habitam, quanto mais criativas estas pessoas forem e quanto mais estas pessoas estiverem interconectadas, mais criativa será a cidade, pois em um ambiente em que a criatividade é estimulada, pessoas se desenvolvem profissionalmente e pessoalmente de maneira mais talentosa, resultando em uma economia criativa pujante em uma cidade inspiradora e instigante.

A economia mundial foi pautada por milênios em uma base agrária, após passou a ser pautada pela industrialização pelo menos por mais 200 anos, passando pela sociedade da informação com a criação da internet e nos tempos atuais fala-se em uma sociedade com sua economia pautada pela inovação e sobretudo pela criatividade (LANDRY, 2011).

Deve-se considerar neste cenário de mudanças globais, que toda mudança econômica resulta também em uma mudança na ordem social, acarretando em novos aprendizados e na demanda de novos tipos de serviços. A administração do que já é conhecido cede lugar à construção de algo ainda desconhecido, mas que já é identificado, ainda que mesmo lpor uma parte apenas da sociedade como algo vantajoso (LANDRY, 2013). Tais mudanças, entretanto, não ocorrem de maneira suave e linear, acarretando em atores que ganham e atores que perdem algo nestas transições nas cidades. Existem cidades que se posicionam como criativas, mas que sofrem problemas de uma má gestão e que possuem grande parte da sua população em situação de pobreza.

O conceito de uma cidade criativa está além de sua capacidade nas artes, nas manifestações culturais e artísticas, mas também na sua capacidade criativa para solucionar problemas, buscar a igualdade social 
para seus cidadãos e buscar soluções inventivas para sair de crises econômicas (REIS, 2011 ; LANDRY, 2013; REIS \& KAGEYAMA, 2011; VIVANT, 2012).

Na década de 1970, houve uma propagação de ideias acerca de um potencial desaparecimento das grandes cidades, uma vez que os centros de produção industrial estavam sendo transferidos para a Ásia e outros lugares de mão-de-obra mais atrativas para as grandes indústrias. Neste período, inclusive cidades como Nova lorque (ou New York) quase foram a falência em função desta evasão industrial (LANDRY, 2013; 2011). Entretanto, apenas uma década depois, $\mathrm{Na}$ década de 1980, as grandes cidades começaram a ressurgir em uma nova lógica, em que sua atratividade passou a consistir em seu potencial em promover elementos que estimulem o aprendizado, as trocas, a conectividade em redes e uma vida social e agenda artística intensa. Neste novo cenário, a cidade passou a atuar como uma aceleradora de oportunidades e um denso de sistema de comunicação (LANDRY, 2013).

Do ponto de vista das instalações físicas de uma Cidade Criativa, é muito comum o reaproveitamento e a revitalização de espaços abandonados, degradados e ociosos, os quais são transformados em espaços úteis, requalificados gentrificados. Este movimento de revitalização já é visto em diversas partes do mundo, em que centenas de antigos galpões, galerias, depósitos, fábricas, estações ferroviárias e as mais diferentes instalações foram reformadas e transformadas em centros culturais, incubadoras, novas empresas, novos espaços de convivência urbana, etc. Estes espaços outrora degradados, geralmente possuíam uma estrutura ampla que possibilita arranjos criativos para seu reaproveitamento e sua transformação em um novo espaço social e criativo (LANDRY, 2013; 2011; KAGEYAMA, 2011).

Ser ou tornar-se uma Cidade Criativa, entretanto, não se resume apenas a instalações físicas com arranjos e design criativos, mas sim a uma mentalidade coletiva que torna a cidade mais dinâmica, estrategicamente ágil e continuamente criativa, pois não existe um ponto fixo de criatividade que a cidade possa se estabelecer como criativa se não houver a contínua manutenção dos projetos que a elevaram a esta categoria de Cidade 
Criativa (LANDRY, 2013). Devem ser explorados todos os elementos existentes na cidade, ou seja, todo o potencial criativo existente em sua simbologia, crenças, folclores, patrimônio, tradições, lembranças, rituais, gastronomia típica, nas aptidões e talentos das pessoas, nos produtos locais, artesanatos, bem como suas paisagens naturais, tais como, clima, topografia, praias, parques, etc. (LANDRY, 2013).

Os planejadores urbanos devem, portanto, identificar estes potenciais nas cidades, utilizando-os de forma a maximizar estes recursos, incentivando iniciativas culturais que projetem as cidades para o futuro, uma vez que "a cultura ajuda a entender de onde um local se origina, por que ele é do jeito que é e como isso pode determinar seu potencial. Esse enfoque chama a atenção para o que é característico, incomparável e especial" nas cidades (LANDRY, 2013, p. 31).

O fato de uma cidade ser criativa não significa que ela consiga contemplar todas os anseios de sua população de forma consensual. $\bigcirc$ desafio consiste justamente em saber gerir a cidade fazendo com que as similaridades fluam para uma convergência que seja mais relevante para a população que seus tensionamentos de opiniões. Os gestores de uma Cidade Criativa são, portanto, conectores, encorajadores e facilitadores (LANDRY, 2013).

Florida (2011), chegou à conclusão em sua pesquisa de que o crescimento econômico de determinadas regiões não era resultado apenas das empresas que ali estavam instaladas, mas por serem lugares em que existiam tolerância, diversidade e abertura à criatividade. Estes são os lugares onde as pessoas criativas de todos os tipos querem estar, pois constituem um meio social e cultural aberto a todas as formas de criatividade. As interações vivenciadas nestes espaços são essenciais ao processo criativo, uma vez que a criatividade nasce de um ato de síntese em que o ser humano necessita de estímulos para criar e sintetizar a partir de referências que possam ser descontruídas e transcendidas (FLORIDA, 2011). 
Florida (2011) desenvolveu em sua longa pesquisa sobre a classe criativa, a teoria dos "3 Ts" em que ele defende que uma cidade para fomentar seu potencial criativo e assim se desenvolver economicamente, precisa reunir concomitantemente as condições que ele denomina de os "3 Ts" Tecnologia, Talento e Tolerância. De acordo com Florida (2011), a tecnologia em uma cidade está relacionada ao seu número de patentes per capta, à inovação, desenvolvimento de novos softwares, produtos eletrônicos, biomédicos e serviços como os relacionados à engenharia. Já uma cidade com um bom índice de tolerância é uma cidade que possui uma baixa barreira à entrada de pessoas, com ampla diversidade cultural. O talento em uma cidade está relacionado ao seu capital humano, ou seja, às pessoas criativas de todas as áreas profissionais que por ali circulam.

\section{LISBOA: Capital Criativa da Europa}

Na última estimativa populacional de Portugal, realizada pelo Instituto Nacional de Estatística de Portugal (INE), em 31 de dezembro de 2016 haviam 10.309.573 milhões de pessoas residentes no país. Deste número, 504.964 pessoas residem em Lisboa (INE, 2017).

Lisboa é uma das 50 melhores cidades do mundo para se viver, de acordo com a consultora Mercer Os critérios levam em conta fatores como o ambiente social e político da cidade, os serviços públicos, habitação e bens de consumo. Além disso, um estudo de 2015 do MIPEX (Migrant Integration Policy Index) mostra Portugal em segundo lugar numa lista de países mais acolhedores com imigrantes. (RIBOLDI, 2016).

"Lisboa parece ter a mistura ideal entre o velho e o novo na arquitetura, uma cena cultural efervescente, incentivos para empresas jovens inovarem, custo de vida baixo e outros fatores mais subjetivos - alguns dizem que a luz da cidade é inconfundível e inspiradora" (FREITAS, 2015).

Espalhada pela cidade, a arte urbana interage com a arquitetura tradicional, toma conta de bairros inteiros, que se transformam em galerias a céu aberto, e serve também como ferramenta de inclusão social em projetos 
como o Lata 65, uma organização sem fins lucrativos que atua desde 2012 ensinando a idosos a arte do graffiti. No projeto, são realizados workshops ministrados por alguns dos melhores artistas urbanos da atualidade (LATA 65, 2017).

O aumento crescente do interesse por Lisboa, muito estimulado pela repercussão de seu crescimento socioeconômico, fez com que a prefeitura da cidade lançasse recentemente um manual do imigrante e um portal para orientar aqueles que desejam migrar (ALTO COMISSARIADO PARA AS MIGRAÇÕES, 2017).

Em 2013, de uma iniciativa conjunta da prefeitura de Lisboa com empresas privadas nasceu ao projeto Startup Lisboa, uma aceleradora de empresas jovens que oferece estrutura e aconselhamento para empresários na cidade (STARTUP LISBOA, 2017).

De acordo com Martins (2011), é a qualidade dos espaços públicos que proporciona ambientes distendidos, que melhor acolhe iniciativas criadoras, que favorece a inclusão social e melhor recebe a diversidade, que mais tolera e integra. Ideias, conhecimento, ação. Em suma, criação. É, assim, importante que esta relação entre quem tem a força das ideias e quem tem o poder da força se desenvolva, no tempo e no espaço da cidade, de forma harmoniosa, propondo, promovendo e gerando ambientes criativos. Lisboa possui diversos espaços criativos, ambientes disruptivos e estimulantes para a troca de ideias, experiências e de convívio multicultural. Entre tais ambientes, pode-se destacar a LX Factory e o Village Underground Lisboa como cases de sucesso de locais férteis para os novos negócios.

○ Village Underground Lisboa, possui uma estrutura arquitetônica original que utiliza containeres transformados em escritórios e dois ônibus transformados em cafetaria e sala de reuniões. Por trata-se de uma incubadora certificada para as indústrias criativas, um espaço de cowork e espaço de eventos multicultural, tem atraído a comunidade criativa de Lisboa para suas instalações. (VILLAGE UNDERGROUND LISBOA, 2017). 
Já a LX Factory trata-se de uma ilha criativa ocupada por profissionais da indústria criativa nas áreas da moda, publicidade, comunicação, multimídia, arte, arquitetura, música, etc. Uma fábrica de experiências onde se torna possível intervir, pensar, produzir, apresentar ideias e produtos num lugar que é de todos, para todos (LX FACTORY, 2017).

"Um dos setores com maior potencial de crescimento futuro na cidade de Lisboa é o da Economia Criativa, entendida aqui como um setor económico determinante para a cidade, entrecruzando diferentes realidades económicas, socioculturais e tecnológicas, dinamizado por inúmeros atores em constante diálogo e transformação" (CÂMARA MUNICIPAL DE LISBOA, 2018).

Estão a ser desenvolvidos processos interativos entre a iniciativa privada e pública que podem resultar em situações "win-win" desejando a Câmara Municipal de Lisboa tornar mais visível a dinâmica da economia criativa e continuar a fomentar a interação entre as suas próprias atividades com instituições privadas e outras entidades públicas (CÂMARA MUNICIPAL DE LISBOA, 2018).

A título exemplificativo enumeram-se alguns casos emblemáticos do dinamismo criativo em Lisboa (Câmara Municipal de Lisboa, 2018):

- Lx Factory;

- Mude - Museu do Design e da Moda;

- Fundação Calouste Gulbenkian;

- Fábrica de Braço de Prata;

- Santos Design District;

- Bairro Alto Astral;

- Experimenta Design;

- Trienal de Arquitetura;

- Moda Lisboa;

- Lisboa \& Estoril Film Festival;

- CCB - Coleção Berardo; 
- Dinamização de espaços municipais com a sua disponibilização de ateliers para artistas.

- Lisboa tem apostado também no empreendedorismo e inovação, de que é exemplo a abertura recente da incubadora da Baixa.

\section{Metodologia}

Para o desenvolvimento dessa investigação foi utilizado o método exploratório descritivo com análise de cunho qualitativo. Como procedimento de coleta de dados, foi elaborado um questionário com 11 perguntas, sendo quatro qualitativas e sete quantitativas em escala de 0 a 10. $O$ link de acesso ao questionário foi divulgado nas redes sociais e entre os contatos da pesquisadora e as respostas foram aceitas por um período de 3 dias (de 11 a 13 de dezembro de 2017).

Foi realizado um pré-teste para a aplicação do questionário, em que foi solicitado a algumas pessoas que lessem o instrumento de coleta de dados e retornassem com dúvidas e observações acerca das questões propostas. Aaker, Kumar e Day (2007) afirmam que o pré-teste tem como propósito assegurar que o questionário atinja as expectativas do pesquisador, aumentando a garantia de que as informações necessárias serão obtidas a partir das perguntas elaboradas. O principal objetivo do pré-teste é corrigir as deficiências da primeira versão do questionário, tais como, questões longas demais, ausência de variáveis importantes, questões ambíguas, tendenciosas, mal elaboradas. Ainda de acordo com Aaker, Kumar e Day (2007, p. 333), "o pré-teste, para ser eficaz, requer que o pesquisador esteja aberto às críticas e disposto a corrigir as deficiências". Foram levadas em consideração as sugestões recebidas para a revisão de algumas questões e validação do instrumento.

Malhotra (2001, p. 154), define a pesquisa qualitativa como "a metodologia de pesquisa não estruturada, exploratória, baseada em pequenas amostras, que proporciona insights e compreensão do contexto do 
problema". Malhotra (2001) destaca ainda que a pesquisa qualitativa propicia melhor visão e compreensão do contexto do problema.

Segundo Prodanov e Freitas (2013), na pesquisa quantitativa deve-se formular hipóteses e classificar a relação entre as variáveis com o intuito de garantir a precisão e evitar contradições na análise e interpretação dos resultados. A abordagem quantitativa pode ser empregada inclusive nas pesquisas descritivas, principalmente quando se busca a relação causa-efeito entre os fenômenos, através da compreensão e classificação de processos dinâmicos, experenciados por grupos sociais e opiniões de determinado grupo.

A pesquisa realizada também pode ser classificada como de corte transversal. Malhotra (2001, p. 109) descreve o estudo transversal como "um tipo de pesquisa que envolve a coleta de informações de uma dada amostra de elementos da população somente uma vez".

Sendo assim, optou-se pela pesquisa com questões quantitativas, qualitativas e de maneira anônima, para que fosse possível realizar uma comparação que mais se aproximasse da verdadeira opinião dos respondentes sobre Lisboa.

Para a análise das respostas enviadas pelos respondentes, fez-se uso do método de análise de conteúdo. De acordo com Bardin (2004), a análise de conteúdo possibilita a comparação das características de discursos entre si ou a comparação de discursos com as normas a qual fazem parte, também sendo possível comparar os resultados de outras análises de textos específicos, caso estas tenham sido realizadas.

A pesquisa não pretendeu esgotar a temática em pauta, uma vez que existem diversas outras bases de dados que poderiam ser acessadas, bem como a realização de uma pesquisa de campo mais ampla. Entretanto, entende-se que para atingir o objetivo deste estudo e para fins de elaboração deste primeiro ensaio sobre Lisboa no contexto das Cidades Criativas, o referencial teórico utilizado somado à pesquisa respondida por uma amostra de 52 pessoas sejam satisfatórios. 


\section{Resultados e Discussão}

Participaram da pesquisa 52 respondentes, localizados no Brasil, Portugal e Qatar. Através de um familiar da pesquisadora que reside em Lisboa, foi possível obter respostas também de pessoas que vivem ou já viveram em Lisboa.

Serão apresentadas a seguir as respostas obtidas através da pesquisa realizada, bem como a análise de seus resultados.

1) Idade: A idade dos respondentes variou de 17 a 67 anos.

2) Profissão: Os respondentes informaram as seguintes categorias profissionais: Administrador, advogado, analista de Importação, aposentado, artesão, assistente de investigação clínica, auxiliar administrativo, auxiliar de transporte, comprador, confeiteiro, consultor, contador, cuidador de idosos, desempregado, designer, designer gráfico, despachante aduaneiro, do lar, docente, empregado em escritório, empresário, engenheiro, engenheiro civil, estagiário, esteticista, fotógrafo, funcionário público, gerente administrativo, gestor, médica dentista, pesquisador, planejador logístico, publicitário, recepcionista e relações públicas.

3) Cidade onde mora: Os respondentes residem nas cidades de Arroio do Meio/RS, Cáceres/MT, Campo Bom/RS, Canoas/RS, Corroios/Portugal, Doha/Qatar, Gramado/RS, Imbituba/SC, Ivoti/RS, Lisboa/Portugal, Nova Santa Rita/RS, Novo Hamburgo/RS, Oeiras/Portugal, Palmela/Portugal, Pareci Novo/RS, Porto Alegre/RS, Rio Grande/RS, Rosário do Sul/RS, Sacavem/Portugal, São Leopoldo/RS, São Paulo/SP e Viamão/RS.

4) De que forma os respondentes conhecem Lisboa: $24,1 \%$ dos respondentes residem em Lisboa; 11,1\% já residiu em Lisboa; 16,7\% possui amigos e/ou familiares que vivem em Lisboa; $13 \%$ já visitou a 
cidade; 29,6\% conhece Lisboa por ler notícias/assistir reportagens/etc. sobre a cidade; $5,5 \%$ conhece de alguma outra forma.

5) Você moraria em Lisboa? $63 \%$ dos respondentes afirmaram que sim, que morariam em Lisboa; 5,5\% responderam que não morariam em Lisboa; $16,7 \%$ responderam que talvez morariam em Lisboa e 14,8\% responderam que já vivem em Lisboa. Pode-se observar que neste caso os percentuais apontam que parte dos respondentes que já vivem em Lisboa selecionaram a opção que "sim" para esta pergunta ao invés de selecionar que já vivem na cidade.

6) Justificativa à resposta na questão 5:

Dentre os participantes da pesquisa que responderam "sim" quanto a morar em Lisboa, houveram as seguintes justificativas:

Atmosfera positiva e agradável; identidade; diversidade e acolhimento.

Me identifico com o estilo de vida deles.

Pela cultura local, receptividade do povo e segurança

Moraria em Lisboa pela qualidade de vida, moeda valorizada, mesmo idioma e muitos outros benefícios.

Eu moraria la pois é um lugar que tem um ritmo de vida mais tranquilo do que o Brasil, a segurança nas ruas é muito melhor que a do Brasil, e apesar do custo de vida ter subido bastante nos últimos anos ainda é um dos mais baixos pra quem quer morar na Europa.

É uma cidade cosmopolita, segura, com uma elevada qualidade de vida.

Pela beleza da cidade, sua história e qualidade de vida e por possuir similaridades culturais ao Brasil

Tranquilidade; diversas opções gastronômicas; segurança.

Por ser um país da Europa deve ter a mesma organização e modo de viver dos demais países.

Considero a cidade linda e cheia de atrativos.

Pelas pessoas que fiz parece ser uma cidade muito boa, com uma rica cultura que me interessa muito

Além de ser linda, possui um povo acolhedor..... Dizem sofrer com falta de profissionais qualificados, dando assim a oportunidade de visto para nós Brasileiros!

Sonho da minha vida 
Cidade com ótima qualidade de vida, muito bonita e com uma cultura bem preservada.

País atraente; cultura rica...

Pela beleza da cidade, sua história e qualidade de vida e por possuir similaridades culturais ao Brasil

E uma cidade muito agradável. Com várias opções culturais e no tamanho ideal.

Pela arquitetura antiga, qualidade de vida e sua parecença em alguns aspectos com o Brasil. O idioma seria um deles

Cidade maravilhosa, qualidade de vida, história, tradição e modernidade

vivenciar novas culturas.

É uma cidade fantástica

Vive muitos anos em Lisboa e sempre gostei muito. Trabalho em Lisboa por isso voltaria a viver lá sem problema.

Excelente qualidade de vida; clima, tráfego, monumentos, diversão...

É uma cidade maravilhosa!!

É uma metrópole europeia que oferece os benefícios do desenvolvimento econômico, com as facilidades da cultura mais próxima da brasileira.

Por ser uma cidade muito agradável, inspiradora, cosmopolita e com uma luz maravilhosa.

Caso trabalhasse na cidade de Lisboa

Moraria pela qualidade de vida que se tem lá.

Segurança, Tranquilidade, Easy going

Lisboa é uma cidade fantástica nos mais diversos aspectos, onde as pessoas podem ter uma excelente qualidade de vida (transporte, saúde, educação), além do setor criativo e cultural que está em franca expansão.

Lisboa é uma das mais importantes cidades do Continente Europeu, pólo turístico, econômico e cultural onde considero ser um ótimo lugar para se morar, trabalhar.

Dentre os respondentes que afirmaram que não viveriam em Lisboa, sua justificativa para tal resposta foi:

Índice alto de desemprego

Me parece uma cidade com um bom custo e qualidade de vida, além de oferecer diversas opções culturais.

Gosto de viver perto de Lisboa, no centro não devido ao trânsito intenso e acho as casas pequenas e com um custo excessivo. 
Com relação aos participantes que responderam que talvez viveriam em Lisboa, houveram as seguintes justificativas:

Já estou estabelecido profissionalmente no Brasil

Nunca pensei sobre isto...mas se recebesse um convite moraria sim...acho lindo demais

Não conheço a cidade, porém se tiver atrativos poderia vir a me interessar em morar lá.

Acredito que seja uma cidade aconchegante e muito bela

Parece ser um lugar ótimo de morar...

Se houvesse uma boa oportunidade de emprego e moradia sim.

Caso tenha uma boa oportunidade de emprego e moradia.

Não conheço muito bem.

Um país que gosto muito

Os residentes em Lisboa comentaram sobre a cidade diversos aspectos positivos da cidade, justificando sua opção de moradia:

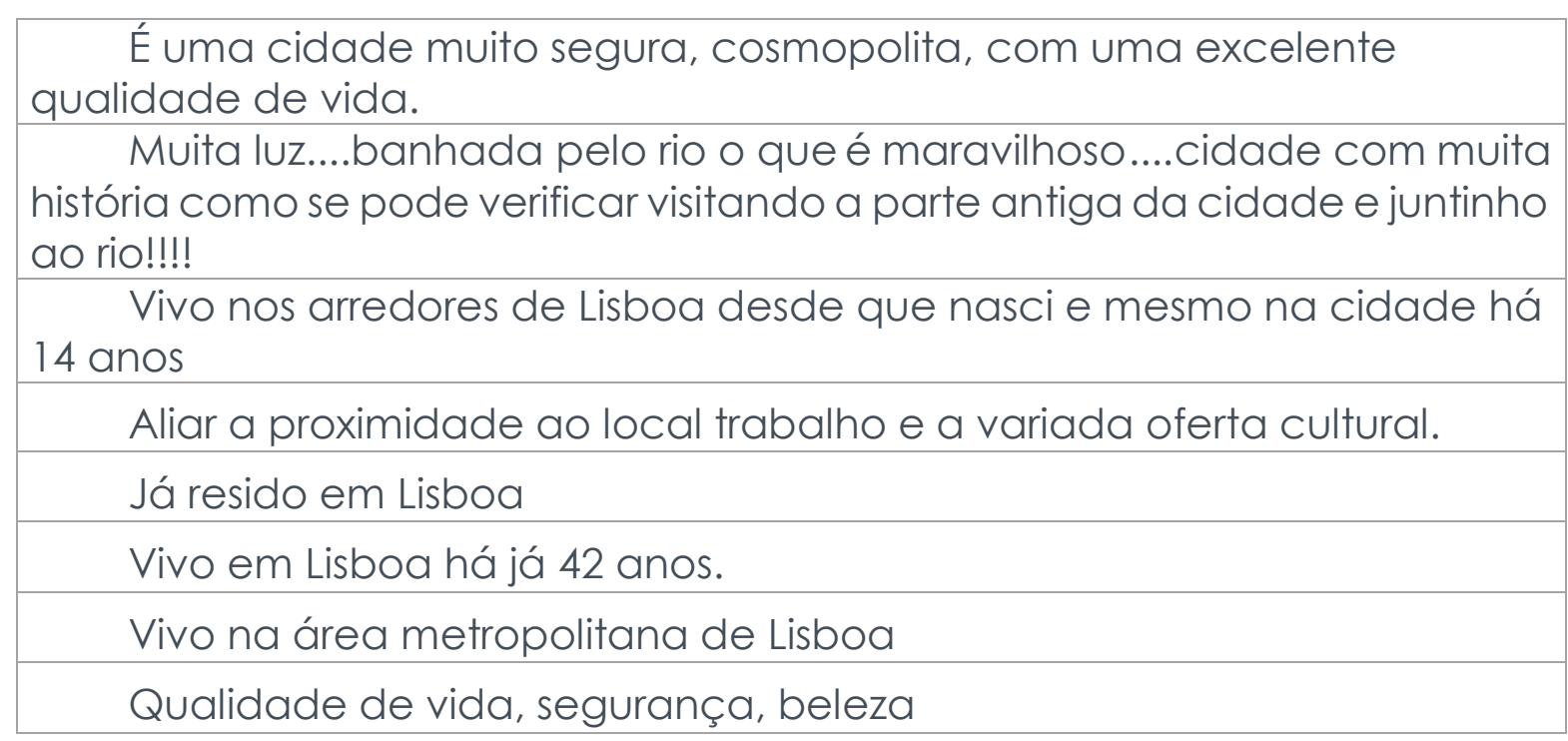

Os respondentes que já residiram em Lisboa também comentaram sobre os benefícios e diferenciais da cidade:

Tranquilidade; diversas opções gastronômicas; segurança.

Cidade maravilhosa, qualidade de vida, história, tradição e modernidade 
Vive muitos anos em Lisboa e sempre gostei muito. Trabalho em Lisboa por isso voltaria a viver lá sem problema.

Excelente qualidade de vida; clima, tráfego, monumentos, diversão

Quanto ao índice de tolerância existente em Lisboa, apresentou-se no questionário a seguinte definição deste conceito: De acordo com Richard Florida (2011), uma cidade com um bom índice de tolerância é uma cidade que possui uma baixa barreira à entrada de pessoas, com ampla diversidade cultural. E a seguir ao conceito foi solicitada a seguinte classificação:

7) Quanto numa escala de 0 a 10 você considera Lisboa uma cidade com um bom índice de tolerância e diversidade? Considerando 0 para nada tolerante/diversa e 10 para muito tolerante/diversa.

O índice de tolerância percebido em Lisboa pelos participantes é bastante alto, tendo variado entre 5 a 10. A maioria dos respondentes classificou Lisboa em 8 (33,3\%) e 10(37\%) no grau de tolerância, ou seja, uma cidade que acolhe a diversidade e com baixa barreira de entrada a novas pessoas.

Com relação à Tecnologia, foi conceitualizado da seguinte maneira na introdução à pergunta: De acordo com Richard Florida (2011), a tecnologia em uma cidade está relacionada ao seu número de patentes per capta, à inovação, desenvolvimento de novos softwares, produtos eletrônicos, biomédicos e serviços como os relacionados à engenharia. E então foi solicitado:

8) Em uma escala de 0 a 10, quanto você considera Lisboa uma cidade tecnológica? Considerando 0 para nada tecnológica e 10 para muito tecnológica.

Os respondentes situaram Lisboa entre 4 e 10 quanto ao seu grau tecnológico. A maioria dos respondentes classificou Lisboa no grau 7 de tecnologia $(25,9 \%)$ e 10 (18,5\%). Diante disso, pode-se considerar que os respondentes avaliam Lisboa como uma cidade altamente tecnológica, o 
que é um dos 3 pilares de Richard Florida para uma cidade ser uma Cidade Criativa.

Com relação ao terceiro "T" de Richard Florida - o Talento, foi apresentado o seguinte conceito anterior à questão: $\bigcirc$ talento em uma cidade está relacionado ao seu capital humano, ou seja, às pessoas criativas de todas as áreas profissionais que por ali circulam (FLORIDA, 2011). E após perguntou-se:

9) Em uma escola de 0 a 10, quanto você considera que Lisboa é habitada por pessoas talentosas? Considerando 0 para nada talentosas e 10 para muito talentosas.

A maioria dos respondentes $(33,33 \%)$ classificou em 8 o grau de pessoas talentosas que habitam Lisboa, seguido de $27,8 \%$ de respostas a situando em 9 e $24,1 \%$ a situando no grau máximo de talento. $O$ grau mais baixo indicado foi 6 .

Dessa forma, os respondentes percebem Lisboa como uma cidade habitada por pessoas talentosas das mais diferentes áreas.

A Cidade Criativa mantém vivas sua cultura, sua história e suas tradições, sendo receptiva a novas influências e incorporando à sua cultura novas ideias (LANDRY, 2013).

10) Diante do conceito acima exposto, você considera Lisboa uma Cidade Criativa? Por quê?

Os respondentes trouxeram diversos aspectos positivos relacionados a uma cidade criativa. Alguns não justificaram sua resposta mas todos afirmaram que consideram a cidade de Lisboa de alguma forma ou em algum grau uma Cidade Criativa, como pode-se observar no quadro de respostas a seguir:

Sim, Lisboa busca melhorar as oportunidades aos cidadãos e gerar desenvolvimento mantendo a cultura e tradição do seu povo. É uma cidade que se reinventa e está receptiva a novas ideias.

Busca inovação mantendo as tradições e historicidade local.

Lisboa investe na proposta da economia criativa como fator de desenvolvimento 
Sim, pela diversidade e por enfatizar sua própria cultura

Sim. Uma cidade criativa.

Porque ela mantém sua história e suas tradições.

Depois da crise enfrentada por Portugal. o pais iniciou inúmeras iniciativas para ressarce sua economia. baixaram o custo de vida por exemplo tornou o pais bastante atraente para os visitantes. também ouve um incentivo de polos tecnológicos lançando o projeto Startup visando incentivar empresas jovens, e muitas outras inovações como na arte urbana, etc

Lisboa mantém viva sua cultura em todos os cantos da cidade.

Contudo, não percebi a questão da incorporação de novas influencias externas.

Sim, pois se ouve falar muito que o povo de Portugal mantém as tradições.

Sim. Creio que é uma das cidades que mais preserva sua história ao mesmo tempo que incorpora novos atrativos.

Por manter viva a sua cultura

Sim, aparentemente mantém vivas suas tradições e culturas, bem arraigadas às pessoas

Após atravessar uma crise, teve que se reinventar! Do limão fizeram uma limonada! Festivais, oportunidades, apresentações, oportunidades!

Sim

Sim, cultura bem preservada e povo muito receptivo.

Sim, pelo pouco que ouvi falar, parece que ela tem todos os pontos para ser uma cidade criativa.

Sim

Sim... Porque a história está viva na cidade

Sim... Cidade receptiva a várias culturas

Considero Lisboa uma cidade criativa. Aproveitou muito vem a integração na União europeia atraindo investimentos em infraestrutura. Tem a vantagem de ter um custo de vida/laboral mais barato em relação às demais grandes capitais europeias e se aproveita bem da proximidade com o Brasil pra se colocar melhor.

Sim, pois conserva muito das coisas antigas

Sim, pois mantém viva muitas tradições, assim como, parece absorver o novo de maneira a não deixar de lado sua cultura histórica.

Sim, pois é uma cidade que concilia maravilhosamente bem a tradição com a modernidade

Lisboa é um espelho de Portugal, um país que transformou a sua cultura ao longo dos séculos através dos descobrimentos. É algo muito enraizado.

Precisamente pelo número de Pessoas que me vou apercebendo de gente talentosa que ajuda precisamente a3 criatividade e também pelos diversos eventos que atualmente esta cidade nos oferece 
Sim. Pretende manter a história e o tradicional mas procura novas ideias. Moderadamente criativa. Acredito que é necessário uma maior uma maior incorporação com a cultura local.

Existem bastantes pessoas criativas, pena é não darem o devido valor. Sim

Sim. Pelos critérios em cima indicados

Sim. Penso que Lisboa Tem muitos bairros antigos, com habitantes com tradições e hábitos muito enraizados mas acolhe bem os jovens, as pessoas de outros países.

A mudança a que assisti em Lisboa nos últimos 40 anos tem a ver com a evolução do país em geral e com a aplicação de boas ideias em particular

Sim. Tem muita diversidade de coisas para fazer e há sempre algo novo acontecendo

Absolutamente!! Exactamente porque mantém viva a sua cultura, história e tradições não deixando de ser totalmente permeável à inovação e criatividade...

Sim

Considero uma cidade que incentiva a indústria criativa, porém localmente. A marca Lisboa não está diretamente associada a criatividade, ponto que precisa ser repensado para atração de capital intelectual de nível mais elevado.

Está aberta a novas tecnologias. É inovadora.

Sim, pois carrega consigo a história e a cultura de um País explorador e católico.

Sim. Cultivam-se algumas das tradições das vivências e história da cidade e interam-se/ aculturam-se novos conceitos trazidos por outros países

$\operatorname{sim}$

Sim, porque mantém viva sua tradição e incorpora novas ideias de outras culturas

Diversidade de origens, culturas e soluções

Sim

Sim. Transporte eficiente, boa educação escolar etc

Por que consegue se renovar mantendo suas tradições como base.

Tem muitos eventos, diversificados

Sim. Lisboa é uma cidade criativa, pois é uma mistura do tradicional com o tecnológico, possui diversos espaços disruptivos, startups, etc e a população está inserida nestes espaços.

Considero criativa, pois assim como sua história e tradições são preservadas e cultuadas, há uma Lisboa moderna, voltada para o futuro.

E para finalizar a pesquisa, foi realizado o seguinte questionamento: 
11) O que você mais aprecia em Lisboa?

A atmosfera e receptividade do seu povo.

estilo de vida

Receptividade e abertura em âmbito socioeconômico.

Arquitetura e gastronomia

a beleza, a segurança etc.

a cultura

A beleza e qualidade de vida da cidade

A infraestrutura; cultura e tradições; diversidade gastronômica; custo de vida bom; opções para diversão.

Não conheço a cidade pessoalmente, mas acredito que o modo de viver e a organização devam sem muito bons!

A estética da cidade.

A alegria do seu povo

Paisagens

Sua cultura

A Cultura, culinária e a maturidade em aceitar que estrangeiros cresçam em seu País!

As pessoas vivem melhor

Prédios históricos

Não conheço a cidade.

Lugares lindos, arquitetura belíssima, e o famoso pastel de Belém dizem que é uma delicia

Tudo.

A cultura

A beleza e qualidade de vida da cidade

História cultura e proximidade com o Brasil.

Castelos e torre de Belém

Tradição gastronômica e cultural.

Andar a pé pelas suas ruas, especialmente na Baixa e no Chiado.

A qualidade de vida em geral.

A muita luz que esta cidade irradia...os seus monumentos que são lindíssimos para visitar e como não podia faltar a ótima gastronomia acompanhada de belíssimos restaurantes

As vistas, o contacto com o rio, as ruas e bairros

Os diferentes micro ambientes e locais, arquitectura e bairros distintos. 
A sua história. E a grande diversificação de eventos em que cidades mais pequenas não têm.

a arquitetura

\section{A luminosidade da cidade}

A facilidade de haver grandes centros urbanos, mas ao mesmo tempo conseguirmos fazer uma vida de dia a dia tão simples.

A luz. O azul do céu.

Monumentos, clima

A saudável convivência do passado com a modernidade, entre muitas outras características.

O colorido

Atmosfera que mistura o ar de cidade medieval com a modernidade do século XXI. A mistura de traços, costumes e sabores que cria um ambiente de inebriante, especialmente a noite.

Os espaços verdes. Culturalmente bem-sucedida. Monumentos com muita história, direcionada para o futuro.

Arquitetura

A luz, a diversidade

Porque para além de nela morarem e ser frequentada por pessoas bastante criativas cada vez mais existe estimulo para que a criatividade seja posta em prática

Beleza, segurança

Tolerância, serviços

A cultura

Segurança e hospitalidade

A cultura e arquitetura.

Segurança

A liberdade, a beleza da cidade, a mistura do antigo com o tecnológico. Uma cidade maravilhosa.

Sua preservação histórica, seus costumes e sua receptividade.

É interessante observar que nas respostas encontram-se diversos elementos de uma Cidade Criativa, até mesmo elementos que não foram mencionados na pergunta anterior, que é específica sobre Lisboa ser uma Cidade Criativa. Pode-se observar nas respostas que as pessoas possuem um grande apreço pela cidade de Lisboa, o que a justifica como de fato estar tão em evidência no cenário global contemporâneo. 
De acordo com Martins (2011), existem diversos elementos em Lisboa que a tornam uma Cidade Criativa: "Lisboa, todos o dizemos, muitos o sentimos, tem esse potencial de se afirmar como cidade criativa" (MARTINS, 2011 , p. 83). "As qualidades de uma Cidade Criativa são similares: um senso de conforto e familiaridade, uma boa mistura do velho com o novo, variedade e escolha e um equilíbrio entre o calmo e o vivificante ou entre o risco e a cautela" (LANDRY, 2013, p. 45).

A Cidade Criativa mantém vivas sua cultura, sua história e suas tradições, sendo receptiva a novas influências e incorporando à sua cultura novas ideias (LANDRY, 2013).

Desta forma, pode-se observar ao analisar os dados da pesquisa realizada, que as respostas obtidas confirmam as premissas de uma Cidade Criativa trazidas pela revisão da literatura.

\section{Conclusão}

presente trabalho evidenciou questões importantes no contexto das Cidades Criativas e buscou investigar o que diferencia Lisboa das outras cidades e a faz ser destaque na contemporaneidade pela mídia e no sistema internacional. Os participantes da pesquisa evidenciaram os elementos presentes em Lisboa que a constitui como uma Cidade Criativa, demonstrando grande apreço pela cidade e a reconhecendo como uma Cidade Criativa.

Dentre os elementos apontados, pode-se destacar tanto os aspectos tecnológicos e de inovação, como as características mais voltadas para questões humanas e também por suas belezas naturais e riqueza de seu patrimônio histórico, compondo o que os respondentes consideraram uma cidade que contêm as condições ideais para se viver com grande qualidade de vida: "A atmosfera e receptividade do seu povo; estilo de vida; abertura em âmbito socioeconômico; arquitetura e gastronomia; a beleza, a segurança; a cultura e tradições; a infraestrutura; diversidade gastronômica; custo de vida bom; opções para diversão; a estética da cidade; a alegriado 
seu povo; paisagens; a maturidade em aceitar que estrangeiros cresçam em seu país; prédios históricos; o contato com o rio, as ruas e bairros; a luminosidade da cidade; o azul do céu; monumentos, clima; a saudável convivência do passado com a modernidade, entre muitas outras características; o colorido; atmosfera que mistura o ar de cidade medieval com a modernidade do século XXI. A mistura de traços, costumes e sabores que cria um ambiente de inebriante, especialmente a noite; os espaços verdes; a liberdade, a beleza da cidade, a mistura do antigo com o tecnológico. Sua preservação histórica, seus costumes e sua receptividade". Tais elementos vão ao encontro de sua eleição pelo Observatório das Cidades Culturais e Criativas da Comissão Europeia como a Capital Criativa da Europa para os anos de 2017 e 2018.

No site da Câmara Municipal de Lisboa também é possível encontrar vasto material sobre o investimento na Economia Criativa como um dos pilares estratégicos da administração pública da cidade. Autores renomados desta área, como Richard Florida e Charles Landry, já participaram de congressos e eventos em Lisboa onde destacaram sua visão sobre Lisboa como uma megaregião e Cidade Criativa.

Como limitação da pesquisa, deve-se considerar que a mesma foi aplicada em um curto período de duração, desta forma indica-se como direcionamento para futuras pesquisas que a amostra seja ampliada e que seja realizado um estudo com maior profundidade sobre a percepção das pessoas sobre a cidade de Lisboa.

Por fim, pode-se destacar a importância do tema Cidades Criativas, ressaltando a relevância de serem estimulados mais estudos nesta área pela academia.

\section{Referências}

Aaker, D. A., Kumar, V., \& Day, G. (2007). Pesquisa de marketing. São Paulo: Atlas. 
ALTO COMISSARIADO PARA MIGRAÇÕES. (05 de dezembro de 2017). Fonte: http://www.acm.gov.pt/inicio

Bardin. L. (2004). Análise de conteúdo. 3. Ed. Lisboa: Edições 70.

CÂMARA MUNICIPAL DE LISBOA. (08 de maio de 2018). Fonte:

<http://www.cm-lisboa.pt/investir/setores-estrategicos/economia-criativa>.

Florida, R. (2011). A ascensão da classe criativa e seu papel na

transformação do trabalho, do lazer, da comunidade e do cotidiano. Porto Alegre: L\&PM.

Freitas, A. (05 de dezembro de 2017). Por que Lisboa é a nova capital criativa da Europa. Fonte: <https://www.nexojornal.com.br/expresso/2015/11/13/Porque-Lisboa-\%C3\%A9-a-nova-capital-criativa-da-Europa>.

INSTITUTO NACIONAL DE ESTATÍSTICA - INE (05 de dezembro de 2017). Estimativas anuais da população residente. Fonte: <https://www.ine.pt/xportal/xmain? xpid=INE\&xpgid=ine_indicadores\&indOco $\operatorname{rrCod}=0006031 \&$ contexto=bd\&selTab=tab2.

Landry, C. (2011). Cidade criativa: a história de um conceito. In: Reis, A. C. F.; Kayagema, P. Cidades criativas - perspectivas. São Paulo: Garimpo de Soluções \& Creative Cities Productions.

Landry, C. (2013). Origens e futuros da cidade criativa. São Paulo: SESI-SP editora.

LATA 65 (05 de dezembro de 2017). Workshop de arte urbana para idosos.

Fonte: https://www.facebook.com/Lata65? fref=ts.

LX FACTORY 105 de dezembro de 2017). Fonte: http://www.Ixfactory.com/PT/Ixfactory/

Malhotra, N. K. (2001). Pesquisa de Marketing: uma orientação aplicada. 3. ed. Porto Alegre: Bookman.

PRODANOV, C. C; FREITAS, E. C. de. Metodologia do trabalho científico [recurso eletrônico]: métodos e técnicas da pesquisa e do trabalho acadêmico. 2. ed. - Novo Hamburgo: Feevale, 2013.

Reis, A. C. F. (2012). Cidades Criativas: da teoria à prática. São Paulo: SESI-SP editora. 
Kageyama, P. (2011). Cidade Criativa. In REIS, A. Carla F.; KAGEYAMA, Peter (Orgs). Cidades Criativas: Perspectivas. São Paulo: Garimpo de Soluções.

REIS, A. C. F. (2010). Cidades criativas: soluções inventivas: o papel da copa, das olimpíadas e dos museus internacionais. Recife: FUNDARPE.

Riboldi, B. (05 de dezembro de 2017). Lisboa é eleita a capital criativa da Europa. Conheça os motivos. Fonte: http://www.conexaolusofona.org/lisboae-eleita-a-capital-criativa-da-europa-conheca-os-motivos/

Rodrigues, S. (05 de dezembro de 2017). Lisboa é a cidade com mais dinâmica cultural da Europa. Fonte: http://visao.sapo.pt/actualidade/sociedade/201707-06-Lisboa-e-a-cidade-com-mais-dinamica-cultural-da-Europa.

STARTUP LISBOA. The Lisbon Incubator (05 de dezembro de 2017). Fonte: http://www.startuplisboa.com/.

VILLAGE UNDERGROUND LISBOA (05 de dezembro de 2017). Fonte: http://vulisboa.com/index.php.

Vivant, E. (2012). O que é uma cidade criativa? São Paulo: Editora SENAC.

\section{Contribuições dos autores: o trabalho foi realizado em conjunto:}

Sarita Cruz de Oliveira Ost - levantamento de dados e redação do texto. Mary Sandra Guerra Ashton - estruturação, indicação de bibliografia, conteúdo e revisão.

Marcos Emílio Santuário: orientação 